\title{
Direct Spectrophotometric Determination of Cefuroxime Axetil in Pure Form and Pharmaceutical Dosage Forms
}

\author{
Abdul Aziz Ramadan ${ }^{1}$, Marwa Bakdash ${ }^{2}$ \\ Department of Chemistry, Faculty of Sciences, University of Aleppo, Syria, \\ 11dramadan@scs-net.org, (963)(21)2633136 \\ 22rimi_m88@hotmail.com
}

\begin{abstract}
A simple, direct and cost-effective spectrophotometric method for determination of cefuroxime axetil (CRXA) in pure and tablet dosage forms was applied. This method is based on formation of ion-pair complex ([CRXA]:[BTB]) between CRXA and bromothymol blue (BTB) in chloroform. Beer's law in the optimum experimental conditions using [CRXA]:[BTB] complex is valid within a concentration range of 2.00-50.00 $\mu \mathrm{M}$ (1.021-25.524 $\mu \mathrm{g} \cdot \mathrm{mL}^{-1}$ ). The developed method is applied for the determination of CRXA in pure and its commercial tablets without any interference from excipients with average assay of 96.8 to $101.6 \%$ and the results are in good agreement with those obtained by the HPLC reference method. Associated drugs (sulbactam and linesolid) with cefuroxime axetil are considered to be interfere, while metronidazole can be considered as non-interfere.
\end{abstract}

Keywords: Cefuroxime axetil; Bromothymol blue; Ion-pair complex; Direct spectrophotometric method.

\section{INTRODUCTION}

Chemically cefuroxime axetil (CRXA) is (RS)-1-hydroxyethyl (6R,7R)-7-[2-(2-furyl) glyoxyl-amido]-3(hydroxymethyl)-8-oxo-5-thia-1-azabicyclo[4.2.0]-oct-2-ene-2-carboxylate,72-(Z)-(O-methyl-oxime), 1-acetate 3-carbamate], its trade name is Ceftin, mol. mass of CRXA is $510.475 \mathrm{~g} / \mathrm{mol}$ and $424.38 \mathrm{~g} / \mathrm{mol}$ for cefuroxime (CRX), see Scheme 1 [1]. It is a broad spectrum, semi synthetic cephalosporin antibiotics which is administered for treating variety of bacterial infections such as case of pharyngitis, chronic bronchitis and infection of urinary tract as well as uncomplicated. It is a second generation cephalosporin and can be administered orally as well as in the parenteral dosage form. The mode of action of cefuroxime against the bacteria is upon inhibiting the bacterial wall synthesis by binding to one or many penicillin binding proteins $[1,2]$.

Bromothymol blue $\mathrm{C}_{27} \mathrm{H}_{28} \mathrm{Br}_{2} \mathrm{O}_{5} \mathrm{~S}$ (BTB), acts as a weak acid in solution. It can thus be in protonated or deprotonated form, appearing yellow or blue, respectively. It is bluish green in neutral solution. The deprotonating of the neutral form results in a highly conjugated structure, accounting for the difference in colour. An intermediate of the deprotonating mechanism is responsible for the greenish color in neutral solution, mol. mass of $624.38 \mathrm{~g} / \mathrm{mol}$ [3], see scheme 2 . Bromothymol blue has been used as a reagent to form ion pair complexes with drugs [4].

Scheme 1: Chemical structure of cefuroxime axetil (CRXA).<smiles>CO/N=C(\C(=O)N[C@@H]1C(=O)N2C(C(=O)OC(C)OC(C)=O)=C(COC(N)=O)CS[C@H]12)c1ccco1</smiles> 
Scheme 2: Chemical structure of Bromothymol blue (BTB).

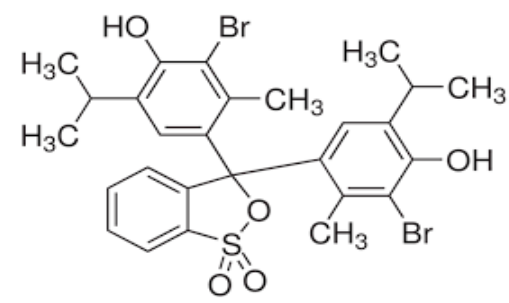

Various spectrophotometric [5-22], High Performance Liquid Chromatographic (HPLC), Reversed-phase high performance liquid chromatography (RP-HPLC), high performance thin layer chromatographic (HPTLC), micellar liquid chromatographic (MLC) [23-37] and voltammetric [38,39] methods have been reported for the determination of cefuroxime.

Three simple accurate spectrophotometric methods have been developed for the estimation of cefuroxime axetil in bulk drug and its solid dosage forms. Method (A) was described about UV spectrophotometric measurement at maximum absorption of $277 \mathrm{~nm}$ while method (B) related to formation of green colored chromogen by utilizing the oxidative coupling reaction between 3-Methyl-2-benzothiozolidine hydrazone (MBTH) and cefuroxime axetil in presence of ferric chloride. It was measured at $624 \mathrm{~nm}$ against reagent blank. Method (C) was based on the formation of pink colored chromogen with para dimethyl amino cinnamaldehyde (PDAC) and it was measured at $537 \mathrm{~nm}$. The beer's law obeyed at the concentration of 5-25 $\mu \mathrm{g} \cdot \mathrm{mL}^{-1}, 1-5 \mu \mathrm{g} \cdot \mathrm{mL}^{-1}$ and 2-10 $\mu \mathrm{g} \cdot \mathrm{mL}^{-1}$ for method $A, B$ and $C$ respectively. The developed analysis could be considered successfully for the determination of cefuroxime axetil in pharmaceutical formulation [17].

A simple, sensitive, accurate, precise and reproducible UV spectrophotometric method for determination of cefuroxime axetil using methanol as solvent was studied. In this method the simple UV spectrum of cefuroxime axetil in methanol was obtained which exhibits absorption maxima $\left(\lambda_{\max }\right)$ at $278 \mathrm{~nm}$. The quantitative determination of the drug was carried out at $278 \mathrm{~nm}$ and Beer's law was obeyed in the range of (0.80-3.60) $\mu \mathrm{g} \cdot \mathrm{mL}^{-1}$. Proposed method was precise, accurate and cost effective [18].

A rapid and reproducible high performance liquid chromatographic method has been developed for the estimation of CRXA in its pure form as well as in pharmaceutical dosage forms. Chromatography was carried out on an ODS C18 column ( $150 \times 4.6 \mathrm{~mm} \times 5 \mu \mathrm{m}$ length), using a mixture of methanol and $0.01 \mathrm{M}$ potassium dihydrogen orthophosphate buffer $(60: 40 \mathrm{v} / \mathrm{v})$ at $\mathrm{pH} 2.0 \pm 0.05$ as the mobile phase at a flow rate of $0.8 \mathrm{~mL} / \mathrm{min}$ and the detection was done at $248 \mathrm{~nm}$ was developed and fully validated for the determination of CRXA. The retention time of the drug was $3.693 \mathrm{~min}$. The method produced linear responses in the concentration range of 0.45 to $80 \mu \mathrm{g} \cdot \mathrm{mL}^{-1}$ of CRXA. The method was successfully validated in accordance to The International Conference on Harmonization (ICH) guidelines and was found to be reproducible for analysis of the drug in parental preparations [27].

New analytical method has been developed for the determination of cefuroxime in pharmaceutical formulations. The method involves the application of high performance Liquid chromatography (HPLC) for the quantitative analysis of cefuroxime. Chromatography was carried out on a C18 column (150 $\times 4.6 \mathrm{~mm}, 3 \mu \mathrm{m})$ with mobile phase comprises of $2.47 \times 10^{-4} \mathrm{M}$ Octane 1-sulfonic acid sodium salt: acetonitrile (65:35). The mobile phase was maintained to flow at a rate of $0.5 \mathrm{~mL} / \mathrm{min}$ and the measurements were made at $254 \mathrm{~nm}$. HPLC method has a shorter analysis time of $10 \mathrm{~min}$. The developed method obeyed the Beer's law in the range of 5- $300 \mu \mathrm{g} \cdot \mathrm{mL}^{-1}$ [32].

In general, HPLC method is more accurate and acceptable. But the instrument is not available in all labs. So, the present work was undertaken with the aim to develop and validate an economic and rapid UV spectrophotometric method with high accuracy and precision. The method will be helpful for the routine estimation of cefuroxime axetil in pure form and in pharmaceutical formulations. 


\section{MATERIALS AND METHODS}

\subsection{Equipment and Materials}

Spectrophotometric measurements were made in Spectro scan 80 DV UV-VIS spectrophotometer with $1 \mathrm{~cm}$ quartz cells. An ultrasonic processor model Power sonic 405 was used to sonicate the sample solutions. The diluter pipette model DIP-1 (Shimadzu), having $100 \mu \mathrm{L}$ sample syringe and five continuously adjustable pipettes covering a volume range from 20 to $5000 \mu \mathrm{L}$ (model Piptman P, GILSON). SARTORIUS TE64 electronic balance was used for weighing the samples.

Cefuroxime axetil (99.9\%) was supplied by Covalent laboratories private limited (India), Linezolid was provided as a gift sample by Balsam Pharma, Al Hawash, Homs, Syria. Sulbactam was provided as a gift sample by Ibn Hayyan Pharmaceuticals, Homs, Syria. Metronidazole was provided as a gift sample by AARTI DRUGS LIMITED Mumbai, India. BTB (97\%) of analytical grade, chloroform were from Sigma-Aldrich. $\mathrm{Na}_{2} \mathrm{CO}_{3}$ and methanol extra pure were from MERCK. All other solvents and reagents were analytical grade chemicals.

Tablet commercial formulations were used for the analysis of CRXA. The pharmaceutical formulations subjected to the analytical procedure were as the follows:

(1) Zednad tablets, Diamond Pharma, Damascus suburb, Syria, each tablet contains $250 \mathrm{mg}$ of CRX (equivalent to $300.7 \mathrm{mg} \mathrm{CRXA)} \mathrm{(Mfg.} \mathrm{4/2018,} \mathrm{Exp.} \mathrm{4/2021)} \mathrm{and} 500 \mathrm{mg}$ of CRX (equivalent to $601.4 \mathrm{mg}$ CRXA) (Mfg. 3/2018, Exp. 3/2021).

(2) Cefrocim tablets, Delta for medicaments, Aleppo, Syria, each tablet contains $250 \mathrm{mg}$ of CRX (equivalent to $300.7 \mathrm{mg} \mathrm{CRXA)} \mathrm{(Mfg.} \mathrm{6/2016,} \mathrm{Exp.} \mathrm{6/2019)} \mathrm{and} 500 \mathrm{mg}$ of CRX (equivalent to $601.4 \mathrm{mg}$ CRXA) (Mfg. 7/2016, Exp. 7/2019).

\subsection{Standard stock solutions}

$1 \times 10^{-3}$ mol..$^{-1}$ of pure CRXA was prepared in chloroform. This solution was prepared by good mixing $5.11 \mathrm{mg}$ of CRXA with $0.10 \mathrm{~g}$ of $\mathrm{Na}_{2} \mathrm{CO}_{3}$, adding $0.30 \mathrm{~mL}$ methanol, and solved in $7 \mathrm{~mL}$ chloroform using ultrasonic for $15 \mathrm{~min}$, filtered over a $10 \mathrm{~mL}$ flask and washed by the same solvent, then diluted to $10 \mathrm{~mL}$ with chloroform. The solution was stored in dark bottle and kept in the refrigerator for not more than a week. The stock solution was further diluted daily just before the use to obtain working solutions of CRXA in the concentration range $2.00-50.00 \mu \mathrm{M}\left(1.021-25.524 \mu \mathrm{g} \cdot \mathrm{mL}^{-1}\right.$ of CRXA).

\section{Stock standard solution of bromothymol blue (BTB) $1 \times 10^{-2} \mathrm{~mol}^{-\mathrm{L}^{-1}}$ :}

Accurately weighed $160.9 \mathrm{mg}$ of bromothymol blue (BTB) was dissolved in chloroform into a volumetric flask $(25 \mathrm{~mL})$ and diluted up to mark with chloroform.

\subsection{Recommended Procedure}

Aliquots of $1 \times 10^{-3}$ mol. $^{-1}$ CRXA solution $(20,50,100,150,200,300,400$ and $500 \mu \mathrm{L})$ containing: 2.00, 5.00, $10.00,15.00,20.00,30.00,40.00$ and $50.00 \mu \mathrm{M}(1.021,2.552,5.105,7.657,10.210,15.314,20.419$ and 25.524 $\mu \mathrm{g} \cdot \mathrm{mL}^{-1}$ ) of CRXA were transferred into a series of $10 \mathrm{~mL}$ calibrated volumetric flasks. Then $0.100 \mathrm{~mL}$ of BTB solution $\left(1 \times 10^{-2}\right.$ mol. $\left.L^{-1}\right)$ was added. The volume was made up to the mark with solvent and the absorbance was measured at $\lambda_{\max } 410 \mathrm{~nm}$ in chloroform, against a similar reagent blank.

\subsection{Procedure for pharmaceutical formulations}

Twenty tablets of each studied pharmaceutical formulation were weighed accurately, finely powdered and mixed well. An amount of the powder equivalent to the weight of tenth tablet was mixed well with $0.10 \mathrm{~g}$ of 
$\mathrm{Na}_{2} \mathrm{CO}_{3}$, adding $0.30 \mathrm{~mL}$ methanol, and solved in $7 \mathrm{~mL}$ chloroform using ultrasonic for $15 \mathrm{~min}$, filtered over a $25 \mathrm{~mL}$ flask and washed by the same solvent, then diluted to $25 \mathrm{~mL}$ with chloroform. This solution contains the follows: 1.0 and $2.0 \mathrm{mg} \cdot \mathrm{mL}^{-1}$ of CRX ( i.e. 1.203 and $2.406 \mathrm{mg} \cdot \mathrm{mL}^{-1}$ of CRXA) for all studied pharmaceutical formulations contain 250 and $500 \mathrm{mg} / \mathrm{tab}$, respectively.

Five solutions were prepared daily by diluting $0.100 \mathrm{~mL}$ from each stock solution of pharmaceuticals for contents: 250 or $500 \mathrm{mg} / \mathrm{tab}$, then $0.100 \mathrm{ml}$ from stock standard solution of BTB was added and adjusted the volume up to $10 \mathrm{~mL}$ with chloroform (these solutions contain 10 or $20 \mu \mathrm{g} \cdot \mathrm{mL}^{-1}$ of CRX respectively and $1 \times 10^{-4}$ mol.L ${ }^{-1}$ of BTB; test solutions).

\section{RESULTS AND DISCUSSION}

\subsection{The effect of solvent}

The effect of the solvents (acetonitrile, benzene, chloroform, dichloroethane, dichloromethane, ethylacetate and toluene) on absorbance of reagent (BTB), formed complex [CRXA]:[BTB] and the difference between them were studied. It was found that chloroform solvent was the best.

\subsection{Absorption Spectra}

UV-Vis spectra of CRXA, BTB and the formed complex CRXA:BTB solutions in chloroform was obtained. CRXA solutions do not absorb in the range $300-600 \mathrm{~nm}$. BTB solutions have small absorption at $\lambda_{\max } 412 \mathrm{~nm}(\varepsilon \approx 210$ $\mathrm{L} \cdot \mathrm{mol}^{-1} \cdot \mathrm{cm}^{-1}$ in chloroform). [CRXA]:[BTB] complex solutions have maximum absorption at $\lambda_{\max } 410 \mathrm{~nm}$ in chloroform, $\varepsilon$ for the complex was $\mathrm{L} \mathrm{mol}^{-1} \mathrm{~cm}^{-1}$, see Figure 1 as example.

Fig.1. UV-Vis spectra in chloroform of: 1$0.5 \times 10^{-4} \mathrm{~mol}^{-1} \mathrm{~L}^{-1}$ of CRXA; $2-5.0 \times 10^{-4}$ mol. L $^{-1}$ of BTB; $3-0.5 \times 10^{-4}$ mol.. $L^{-1}$ ion-pair complex $\left(0.5 \times 10^{-4} \mathrm{~mol}^{-1} \mathrm{~L}^{-1}\right.$ of $\mathrm{CRXA}$ with $5 \times 10^{-4}$ mol. L $^{-1}$ of BTB ); Blank is $5.0 \times 10^{-4}$ mol. L $^{-1}$ of BTB, $4-0.5 \times 10^{-4}$ mol.. L $^{-1}$ ion-pair complex $\left(0.5 \times 10^{-4} \mathrm{~mol}^{-1} \mathrm{~L}^{-1}\right.$ of CRXA with $5 \times 10^{-4}$ mol. $^{-1}$ of BTB); Blank is chloroform, $\ell=1 \mathrm{~cm}$.

\subsection{Optimization of Variables}

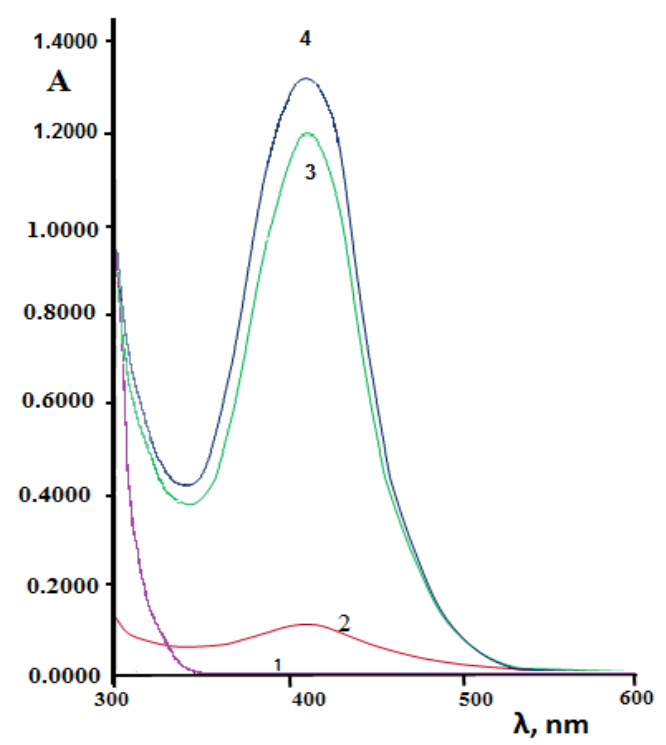

The different experimental parameters affecting the spectrophotometric determination of CRXA through ionpair complex [CRXA]:[BTB] formation with BTB in chloroform was studied in order to determine the optimal conditions for the determination of CRXA.

\subsection{The effect of time and temperature}

The effect of time and temperature on the complex [CRXA]:[BTB] formation was studied within the ranges 5 $120 \mathrm{~min}$ and $15-45^{\circ} \mathrm{C}$. It was found that the formed complex wasn't affected by time or temperature at those ranges. 


\subsection{The effect of BTB concentration}

The effect of BTB concentration on complex [CRXA]:[BTB] formation was investigated. It was observed that the absorbance of the formed complex increased coinciding with increasing the ratio of $C_{B T B}: C_{C R X A}$ until the ratio $(2: 1)$.

\subsection{Stoichiometric Relationship}

\subsubsection{The molar ratio method}

The composition of CRXA:BTB complex were determined by the molar ratio method and Job's method of continuous variation [40]. The stoichiometry of CRXA:BTB complex was studied by molar ratio method according to following equation: $A_{\max }=f([B T B] /[C R X A])$ at $\lambda_{\max } 410 \mathrm{~nm}$ in chloroform. It confirmed that the binding ratio of CRXA:BTB complex is equal to (1:1); where the concentration of CRXA was constant (50 $\mu \mathrm{M})$ and the concentrations of $B T B$ changed from 0 to $200 \mu \mathrm{M}$, see Figure 2. The formation constant of the ion pair complex $[C R X A]:[B T B]$ is $3.12 \times 10^{7}$ in chloroform.

Fig.2. Molar ratio method to calculate binding ratio of CRXA:BTB complex at $\lambda_{\max } 410 \mathrm{~nm}$ in chloroform $([C R X A]=50 \mu \mathrm{M}$, blank is chloroform, $\ell=1 \mathrm{~cm}$ ).

\subsubsection{The Job's method}

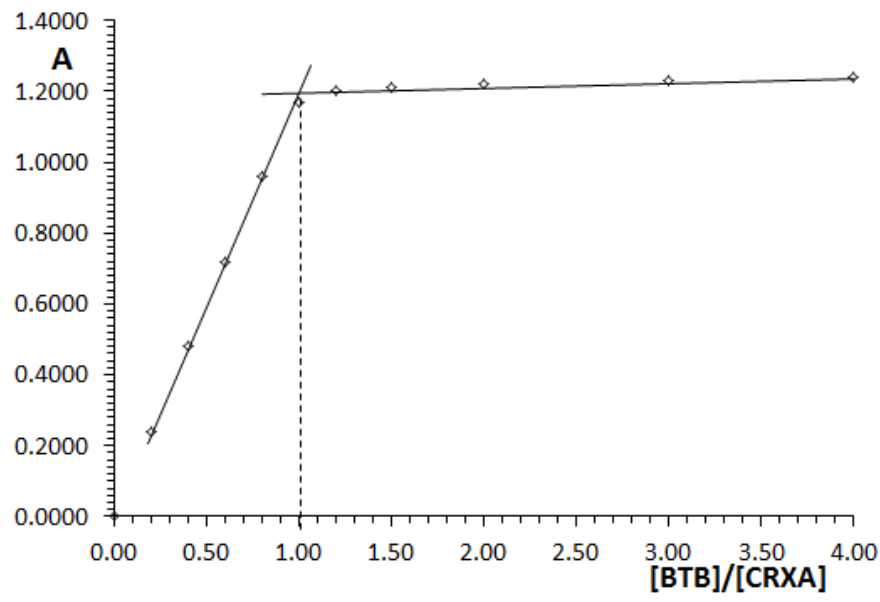

Continuous variation was utilized to check the composition of CRXA:BTB complex at $\lambda_{\max } 410 \mathrm{~nm}$ in chloroform. The absorbance of the complex in used solvent were plotted against the mole fraction $[B T B] /([C R X A]+[B T B])$, where $[C R X A]+[B T B]=50 \mu \mathrm{M}$. The plot reached maximum value at a mole fraction of 0.5 , see Figure 3. This indicated complex formation (CRXA:BTB) in the ratio of $(1: 1)$. The formation constant of the ion- pair complex [CRXA]:[BTB] is $3.5 \times 10^{7}$.

Fig.3. Job's method of continuous variation to calculate binding ratio of CRXA:BTB complex at $\lambda_{\max } 410 \mathrm{~nm}$ in chloroform $([C R X A]+[B T B]=50 \mu \mathrm{M}$, blank is chloroform, $\ell=1 \mathrm{~cm})$.

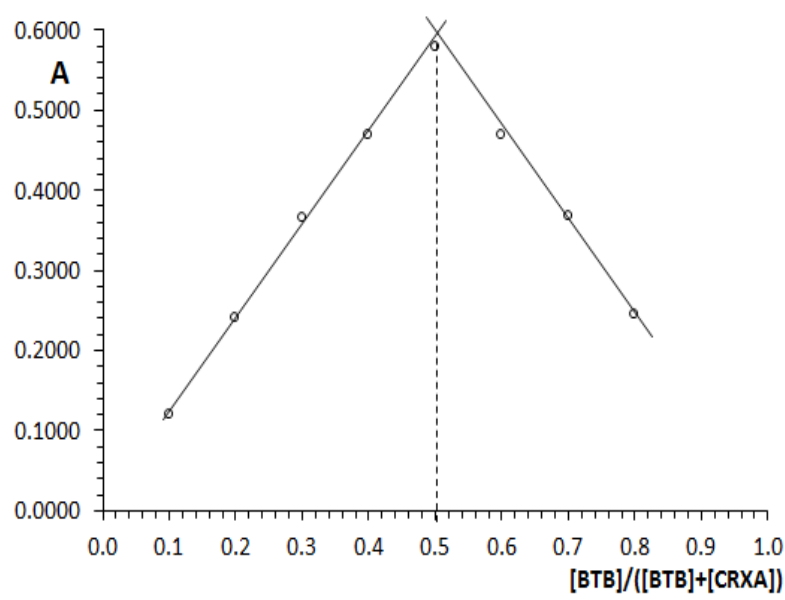

\subsection{Mechanism of reaction}

Anionic dyes such as BTB form ion-pair complexes with the positively charged nitrogen-containing molecule. The colour of such dyes is due to the opening of lactoid ring and subsequent formation of quinoid group (deprotonated). CRXA is reacted with the dye at $\mathrm{pH}<3.8$; (in $\mathrm{pH}>5.4$ and alkaline solution BTB gives blue 
colour). Each drug-dye complex with two oppositely charged ions (positive on the drug and negative on the dye) behaves as a single unit held together by an electrostatic binding [41]. The suggested mechanism of CRXA-BTB ion-pair complex formation is shown in Scheme 3.

i-<smiles>Cc1c(C2(c3cc(C(C)C)c(O)c(Br)c3C)OS(=O)(=O)c3ccccc32)cc(C(C)C)c(O)c1Br</smiles>

Bromothymol blue (BTB)

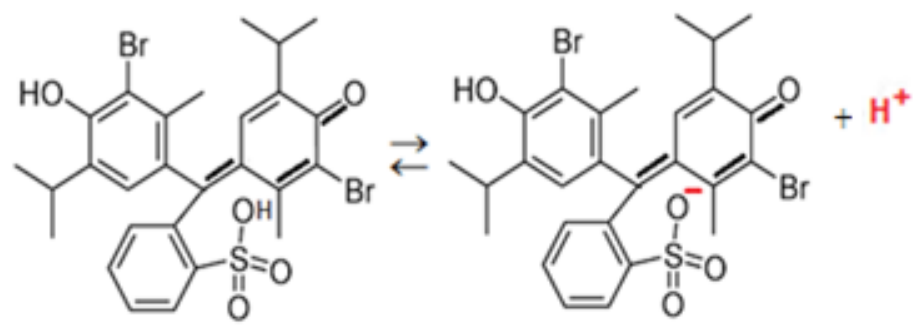

ii-

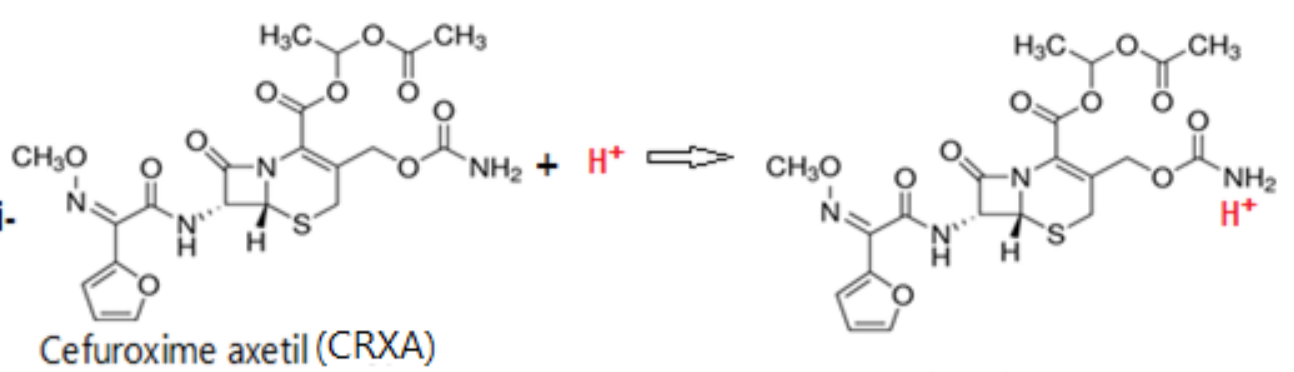

iii-<smiles>CON=C(C(=O)N[C@H]1C(=O)N2C(C(=O)OC(C)OC(C)=O)=C(COC([NH3+])=O)CS[C@H]12)c1ccco1</smiles><smiles>CO/N=C(\C(=O)N[C@@H]1C(=O)N2C(=O)C(COC(N)=O)=C(COC(C)=O)CS[C@H]12)c1ccco1</smiles>

Scheme 3: The possible reaction mechanism of [CRXA]:[BTB] complex formation.

\subsection{Calibration curve}

The calibration curve of CRXA in pure form through complexation with BTB showed excellent linearity over concentration range of $2.00-50.00 \mu \mathrm{M}\left(1.021-25.524 \mu \mathrm{g} \cdot \mathrm{mL}^{-1}\right)$ in presence of $1.0 \times 10^{-4} \mathrm{~mol}^{-\mathrm{L}^{-1}}$ of BTB with good correlation coefficient $\left(R^{2}=0.9996\right)$ in chloroform. Regression equation at $\lambda_{\max }$ was as the follows: $y=0.0241 x+0.0039$ in chloroform. Figures 4 showed the calibration curve of complex ([CRXA]:[ BTB]) in presence of $1.0 \times 10^{-4} \mathrm{M}$ of BTB as example. The spectra characteristics of the method such as the molar absorptivity $(\varepsilon)$ Beer's law, regression equation at $\lambda_{\max }(y=a \cdot x+b)$; where $y=a b s o r b a n c e, a=s l o p e$, $\mathrm{x}=$ concentration of CRXA by $\mu \mathrm{M}, \mathrm{b}=$ intercept, the correlation coefficient, limit of detection (LOD) and limit of quantification (LOQ) and the optimum conditions for spectrophotometric determination of CRXA through ionpair complex formation using BTB in chloroform is summarized in Table 1. 

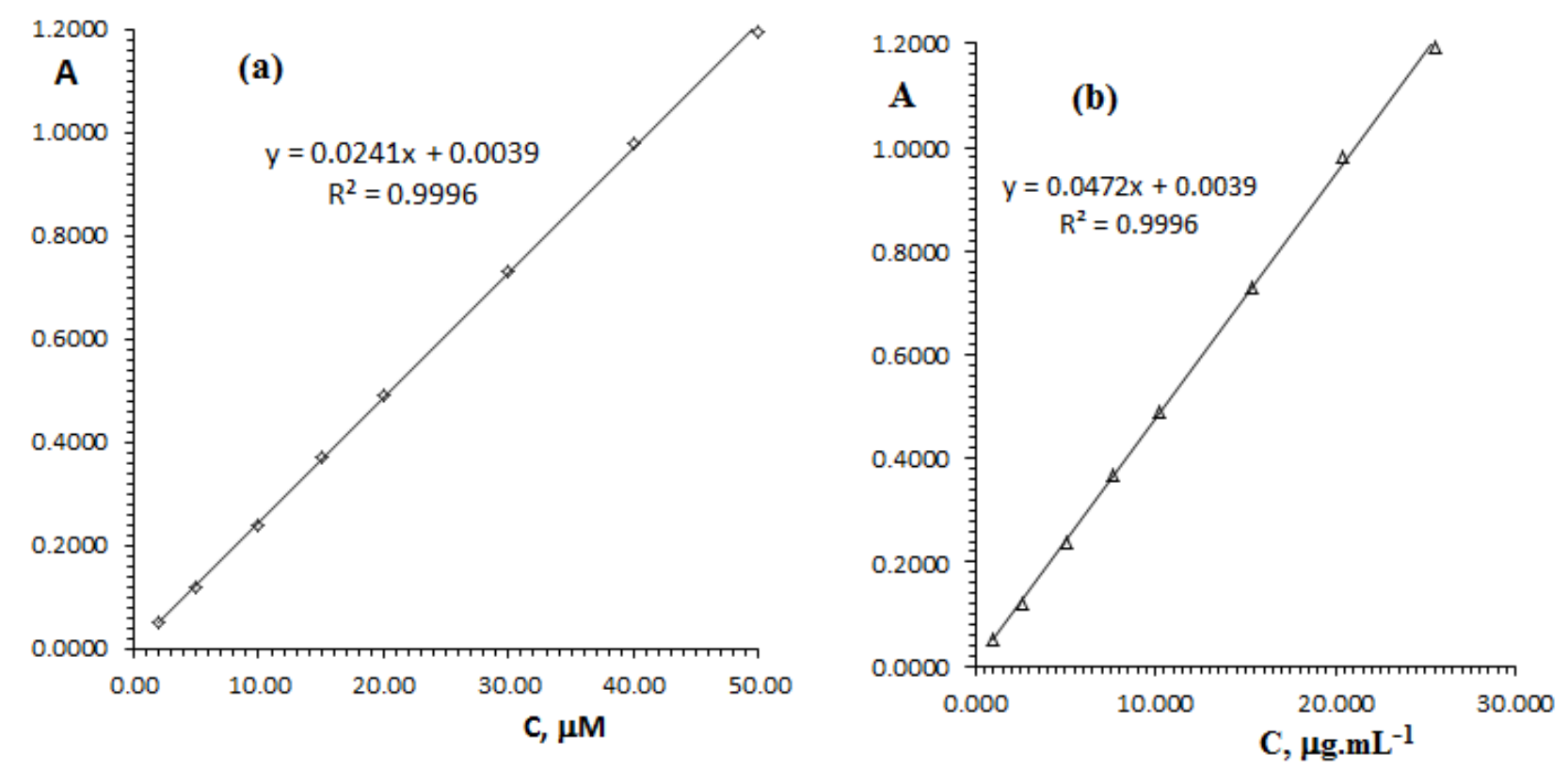

Fig 4: Calibration curve for determination of CRXA according to optimal conditions at $\lambda_{\max } 410 \mathrm{~nm}$ (in present of $1.0 \times 10^{-4} \mathrm{M}$ of BTB) where CRXA:2.00-50.00 $\mu \mathrm{M}$ \{Blank is BTB solution in chloroform $1.0 \times 10^{-4} \mathrm{M} ; \ell=1 \mathrm{~cm}$; a by $\mu \mathrm{M}$ and $\mathbf{b}$ by $\left.\mu \mathrm{g} \cdot \mathrm{mL}^{-1}\right\}$.

Table 1. The parameters established for spectrophotometric determination of CRXA by complex formation with BTB in chloroform.

\begin{tabular}{|c|c|}
\hline Parameters & Operating values \\
\hline$\lambda_{\max }$ of CRXA: BTB complex, $\mathrm{nm}$ & 410 \\
\hline Beer's Law Limit, for $C_{C R X A}, \mu M$ & $2.00-50.00$ \\
\hline Beer's Law Limit, for $C_{C R X A}, \mu g \cdot \mathrm{mL}^{-1}$ & $1.021-25.524$ \\
\hline Molar absorptivity of [CRXA]:[BTB] complex $(\varepsilon)$ L.mol ${ }^{-1} \cdot \mathrm{cm}^{-1}$ & 24000 \\
\hline \multicolumn{2}{|l|}{ Regression equation for [CRXA]:[BTB] by $\mu \mathrm{M}$ at $\lambda_{\max }=410 \mathrm{~nm}$ : } \\
\hline Slope & 0.0241 \\
\hline Intercept & 0.0039 \\
\hline Correlation coefficient $\left(R^{2}\right)$ & 0.9996 \\
\hline $\mathrm{LOD}, \mu \mathrm{g} \cdot \mathrm{mL}^{-1}$ & 0.13 \\
\hline $\mathrm{LOQ}, \mu \mathrm{g} \cdot \mathrm{mL}^{-1}$ & 0.39 \\
\hline RSD\% & 4.2 \\
\hline $\mathrm{C}_{\mathrm{BTB}}: \mathrm{C}_{\mathrm{CRXA}}, \mathrm{M}$ & $\geq 2$ \\
\hline Stability & $6 \mathrm{~h}$ \\
\hline Temperature of solution & $25 \pm 5^{\circ} \mathrm{C}$ \\
\hline
\end{tabular}

$n=5, t=2.776$. 


\section{Analytical results}

Spectrophotometric determination of CRXA through complexation with BTB in chloroform within optimal conditions using calibration curve was applied. The results, summarized in Table 2, showed that the determined concentration of CRXA was rectilinear over the range of 2.00-50.00 $\mu \mathrm{M}\left(1.021-25.524 \mu \mathrm{g} \cdot \mathrm{mL}^{-1}\right)$, with relative standard deviation (RSD) not more than $4.2 \%$. The results obtained from the developed method have been compared with the official HPLC method [27] and good agreement was observed between them.

Table 2: Spectrophotometric determination of CRXA through complex formation with BTB within optimal conditions using calibration curve in chloroform $(n=5, t=2.776)$.

\begin{tabular}{|c|c|c|c|c|c|}
\hline \multicolumn{2}{|c|}{ (Taken) } & \multirow{2}{*}{$\begin{array}{l}\bar{x} \pm S D \\
\mu g \cdot m^{-1} \\
\text { (Found) }\end{array}$} & \multirow{2}{*}{$\begin{array}{l}\bar{x} \pm \frac{t \cdot S D}{\sqrt{n}} \\
\boldsymbol{\mu g} \cdot \mathrm{mL}^{-\mathbf{1}}\end{array}$} & \multirow[b]{2}{*}{ RSD\% } & \multirow{2}{*}{$\begin{array}{l}\bar{x}, \mu g \cdot \mathrm{mL}^{-1} \\
\text { HPLC [27] }\end{array}$} \\
\hline $\begin{array}{l}\mathbf{X}_{\mathbf{i}} \\
\boldsymbol{\mu} \mathbf{M}\end{array}$ & $\begin{array}{c}X_{i} \\
\mu g \cdot \mathrm{mL}^{-1}\end{array}$ & & & & \\
\hline 2.0 & 1.021 & $0.977 \pm 0.041$ & $0.977 \pm 0.051$ & 4.2 & 1.094 \\
\hline 5.0 & 2.552 & $2.460 \pm 0.096$ & $2.460 \pm 0.119$ & 3.9 & 2.500 \\
\hline 10.0 & 5.105 & $5.002 \pm 0.185$ & $5.002 \pm 0.230$ & 3.7 & 5.082 \\
\hline 15.0 & 7.657 & $7.756 \pm 0.279$ & $7.756 \pm 0.347$ & 3.6 & 7.682 \\
\hline 20.0 & 10.210 & $10.299 \pm 0.360$ & $10.299 \pm 0.447$ & 3.5 & 10.346 \\
\hline 30.0 & 15.314 & $15.383 \pm 0.523$ & $15.383 \pm 0.650$ & 3.4 & 15.027 \\
\hline 40.0 & 20.419 & $20.680 \pm 0.682$ & $20.680 \pm 0.847$ & 3.3 & 20.580 \\
\hline 50.0 & 25.524 & $25.235 \pm 0.782$ & $25.235 \pm 0.971$ & 3.1 & 25.046 \\
\hline
\end{tabular}

\section{Applications}

The developed spectrophotometric method was applied to determine CRXA in some pharmaceutical preparations through complex formation by BTB in chloroform according to the optimal conditions. The results of quantitative analysis for CRXA in pharmaceutical preparations were summarized in Table 3 . The Proposed method was simple, direct, specific and successfully applied to the determination of CRXA in pharmaceuticals without any interference from excipients. Average recovery ranged between 99.6 to $101.3 \%$. The results obtained by this method agree well with the contents stated on the labels and were validated by HPLC method [27].

\section{METHOD VALIDATION}

The developed method for simultaneous estimation of CRXA has been validated in accordance with the International Conference on Harmonization (ICH) guidelines [42]. 


\subsection{Specificity}

The specificity of the method was ascertained by analyzing standard CRXA in presence of excipients. There was no interference from the common excipients.

Table 3: Determination of CRX, in some Syrian pharmaceutical preparations using spectrophotometric method through complex formation with BTB in chloroform,

$$
\left.\lambda_{\max } 410 \mathrm{~nm}, \mathrm{n}=5, \mathrm{t}=2.776\right) \text {. }
$$

\begin{tabular}{|c|c|c|c|c|c|c|}
\hline $\begin{array}{c}\text { Tablet dosage } \\
\text { form }\end{array}$ & $\begin{array}{c}\text { Label Claim } \\
\text { of CRX, } \\
\mathbf{m g / t a b .}\end{array}$ & $\begin{array}{c}{ }^{*} \text { Mean } \pm \text { SD } \\
\text { (CRX), }\end{array}$ & RSD\% & Assay \% & $\begin{array}{c}\text { Mean } \pm \text { SD } \\
\text { (CRX), } \\
\mathbf{m g} / \text { tab. } \\
\text { by HPLC [27] }\end{array}$ & Assay \%, \\
\hline \multirow{2}{*}{ Zednad tablets } & 250 & $254 \pm 9.6$ & 3.8 & 101.6 & $253 \pm 7.1$ & 101.2 \\
\cline { 2 - 7 } & 500 & $498 \pm 15.9$ & 3.2 & 99.6 & $499 \pm 9.8$ & 99.8 \\
\hline \multirow{2}{*}{ Cefrocim tablets } & 250 & $242 \pm 9.8$ & 3.7 & 96.8 & $243 \pm 7.2$ & 97.2 \\
\cline { 2 - 7 } & 500 & $506 \pm 16.2$ & 3.2 & 101.2 & $504 \pm 9.6$ & 100.8 \\
\hline
\end{tabular}

\subsection{Linearity}

Several aliquots of standard stock solution of CRXA were taken in different $10 \mathrm{~mL}$ volumetric flask in presence of $1.0 \times 10^{-4} \mathrm{~mol}^{-\mathrm{L}^{-1}}$ of BTB and diluted up to the mark with chloroform such that their final concentrations were 2.00-50.00 $\mu \mathrm{M}\left(1.021-25.524 \mu \mathrm{g} \cdot \mathrm{mL}^{-1}\right)$ for CRXA. Absorbance was plotted against the corresponding concentrations to obtain the calibration graph, see Table 2. Linearity equations obtained were $y=0.0241 x+0.0039\left(R^{2}=0.9996\right)$ for the mentioned range.

\subsection{Precision and Accuracy}

The precision and accuracy of proposed method was checked by recovery study by addition of standard drug solution to pre-analyzed sample solution at three different concentration levels $(80 \%, 100 \%$ and $120 \%)$ within the range of linearity for CRXA. The basic concentration level of sample solution selected for spiking of the CRXA standard solution was $10.210 \mu \mathrm{g} \cdot \mathrm{mL}^{-1}$. The Proposed method was validated statistically and through recovery studies and was successfully applied for the determination of CRXA in pure and dosage forms with percent recoveries ranged from $99.6 \%$ to $101.3 \%$, see Table 4 .

Table 4: Results of recovery studies $(n=5)$.

\begin{tabular}{|c|c|}
\hline Level & Recovery\% \\
\hline $80 \%$ & 99.6 \\
$100 \%$ & 99.4 \\
$120 \%$ & 101.3 \\
\hline
\end{tabular}




\subsection{Repeatability}

The repeatability was evaluated by performing 10 repeat measurements for $15.0 \mu \mathrm{M}\left(7.657 \mu \mathrm{g} \cdot \mathrm{mL}^{-1}\right)$ of CRXA using the studied method under the optimum conditions. The found amount of CRXA ( $\overline{\mathbf{X}} \pm$ SD) $15.191 \pm 0.516$ $\mu \mathrm{M}\left(7.756 \pm 0.264 \mu \mathrm{g} \cdot \mathrm{mL}^{-1}\right)$ and the percentage recovery was found to be $101.3 \pm 3.4$. These values indicate that the proposed method has high repeatability for CRXA analysis.

\subsection{Robustness}

The robustness of the method adopted is demonstrated by the constancy of the absorbance with the deliberated minor change in the experimental parameters such as the change in the concentration of excipients, $C_{\text {Bтв }}(10 \pm 5 \%)$, temperature $\left(25 \pm 5^{\circ} \mathrm{C}\right)$, stability $(6 \pm 0.5 \mathrm{~h})$ and reaction time $(5 \pm 1 \mathrm{~min})$, see Table 5 which indicates the robustness of the proposed method. The absorbance was measured and assay was calculated for five times.

Table 5: Robustness of the proposed spectrophotometric method,

$$
(n=5, t=2.776) \text {. }
$$

\begin{tabular}{|c|c|c|}
\hline \multirow{2}{*}{$\begin{array}{c}\text { Experimental parameter } \\
\text { variation }\end{array}$} & \multicolumn{2}{|c|}{ Average recovery (\%) } \\
\cline { 2 - 3 } & $2.552 \boldsymbol{\mu g} \cdot \mathbf{m L}^{-\mathbf{1}}$ & $15.314 \mathbf{\mu g} \cdot \mathbf{m L}^{-\mathbf{1}}$ \\
\cline { 2 - 3 } $20^{\circ} \mathrm{C}$ & 99.8 & 99.9 \\
$30^{\circ} \mathrm{C}$ & 100.1 & 100.4 \\
\hline Stability & & \\
$5.5 \mathrm{~h}$ & 99.7 & 99.9 \\
$6.5 \mathrm{~h}$ & 100.1 & 100.3 \\
\hline Reaction time & 100.2 & 100.1 \\
4.0 min & 100.4 & 100.0 \\
\hline 6.0 min & & \\
\hline
\end{tabular}

\subsection{Sensitivity (LOD and LOQ)}

The sensitivity of the method was evaluated by determining the LOD and LOQ. The values of LOD and LOQ for CRXA are 0.13 and $0.39 \mu \mathrm{g} \cdot \mathrm{mL}^{-1}$, respectively.

\subsection{The homogenization of tablets}

The homogenization of tablets in terms of the weight and the amount of drug was studied. We found that the mean weight and amount drug in the tablets was $0.7544 \pm 0.0046 \mathrm{~g}$ (i.e. $\pm 0.61 \%$ ), $0.8577 \pm 0.039 \mathrm{~g}$ (i.e. $\pm 4.6 \%$ ) 
for Cefrocim tablets $(250$ and $500 \mathrm{mg} / \mathrm{tab}$ ) and $0.4486 \pm 0.0021 \mathrm{~g}$ (i.e. $\pm 0.47 \%$ ) and $0.8577 \pm 0.0046 \mathrm{~g}$ (i.e. $\pm 0.54 \%$ ) for Zednad tablets ( 250 and $500 \mathrm{mg} / \mathrm{tab}$ ), respectively. While the mean amount drug in the tablets was $254 \pm 1.82 \mathrm{mg} / \mathrm{tab}$ (i.e. $\pm 0.73 \%$ ) and $497 \pm 21 \mathrm{mg} / \mathrm{tab}$ (i.e. $\pm 4.2 \%$ ) for Zednad tablets ( 250 and $500 \mathrm{mg} / \mathrm{tab}$ ) and $244 \pm 6.98 \mathrm{mg} / \mathrm{tab}$ (i.e. $\pm 2.8 \%$ ) and $505 \pm 5.2 \mathrm{mg} / \mathrm{tab}$ (i.e. $\pm 1.03 \%$ ) for Cefrocim tablets ( $250 \mathrm{and} 500 \mathrm{mg} / \mathrm{tab}$ ), respectively; which shows that homogeneity of tablets is good.

\subsection{Interferences}

The presence of 1:1 sulbactam or linesolid in the tablet interfere the determination of cefuroxime axetil (or cefuroxime) by $24 \%$ and $32 \%$, respectively. While metronidazole can be considered as non-obstructive 1:1 (disability less than $5 \%$ ) does not interferes.

\section{CONCLUSION}

The developed spectrophotometric method is simple, direct (extraction-free) and cost-effective for the determination of CRXA in pure and tablet dosage forms was applied. This method is based on formation of ion-pair complex between CRXA and BTB in chloroform ([CRXA]:[BTB]). Beer's law in the optimum experimental conditions using [CRXA]:[BTB] complex is valid within a concentration range of 1.021-25.524 $\mu \mathrm{g} \cdot \mathrm{mL}^{-1}$. The developed method is applied for the determination of CRXA in pure and its commercial tablets without any interference from excipients with average assay of 96.8 to $101.6 \%$. Associated drugs (sulbactam or linesolid) with cefuroxime are considered to be interfere, while metronidazole can be considered as noninterfere.

\section{REFERENCES}

1. British pharmacopoeia. 2009. The Department of Health. Vol I. London: The Stationary office.

2. The Merck Index - an Encyclopedia of Chemicals, Drugs and Biologicals. New Jersey: Merck \& Co. 2001.

3. Thierry M. D. 2014. Substituent effects on absorption spectra of $\mathrm{pH}$ indicators: An experimental and computational study of sulfonphthaleine dyes. Dyes and Pigments. 102:241-250.

4. Rahman N., Najmul S., Azmi H. 2000. Extractive spectrophotometric methods for determination of diltiazem $\mathrm{HCl}$ in pharmaceutical formulations using bromothymol blue, bromophenol blue and bromocresol green. Journal of Pharmaceutical and Biomedical Analysis. 24:33-41.

5. Santosh S., Santosh D., Amit R., Dinesh D., Sai fee M., Mohd H. G. D. 2009. Development and validation of UV spectrophotometric method of cefuroxime axetil in bulk and pharmaceutical formulation. Asian J. Research Chem. 2(2):222-224.

6. Amin A. S., Ragabb G. H. 2004. Spectrophotometric determination of certain cephalosporins in pure form and in pharmaceutical formulations. Spectrochimica Acta Part A 60:2832-2835.

7. Pritam J., Manish P., Sanjay S. 2011. Development and validation of UV-spectrophotometric method for determination of cefuroxime axetil in bulk and in formulation. International Journal of Drug Development \& Research. 3(4):318-322.

8. Game M. D., Sakarkar D. M., Gabhane K. B., Tapar K. K. 2010. Validated spectrophotometric methods for the determination of cefuroxime axetil in bulk drug and tablets. International Journal of Chem Tech Research. 2(2):1259-1262.

9. Omar M. A., Abdelmageed O. H., Attia T. Z. 2009. Kinetic spectrophotometric determination of certain cephalosporins in pharmaceutical formulations. Int. J. Anal. Chem. 2009: 1-12. 
10. Okoye N. N., Nwokedi G. I. C., Ukwueze N. N., Okoye F. B. C. 2007. Spectrophotometric determination of some cephalosporin antibiotics using prussian blue reaction. Scientific Reaserch and Essay. 2(8):342347.

11. Ayad M. M., Shalaby A. A., Abdellatef H. E., Elsaid H. M. 1998. Spectrophotometric and atomic absorption spectrometric determination of certain cephalosporins. Journal of Pharmaceutical and Biomedical Analysis. 18:975-983.

12. Ayad M. M., Shalaby A. A., Abdellatef H. E., Elsaid H. M. 1998. Spectrophotometric determination of certain cephalosporins through oxidation with cerium(IV) and 1-chlorobenzotriazole. Journal of Pharmaceutical and Biomedical Analysis. 20:557-564.

13. Adegoke O. A., Quadri M. O. 2016. Novel spectrophotometric determinations of some cephalosporins following azo dye formation with p-dimethylaminobenzaldehyde. Arabian Journal of Chemistry. 9:S1272-1282.

14. Chaudhari S. V., Karnik A., Adhikary A., Tandale R. S., Vavia P. R. 2006. Simultaneous UV spectrophotometric method for the estimation of cefuroxime axetil and probenecid from solid dosage forms. Scientific Publication of the Indian Pharmaceutical Association. 68(1):59-63.

15. Shinde M. V., Pishawikar S. A., More H. N. 2008. Spectrophotometric determination of cefuroxime axetil from bulk and in its tablet dosage form. Indian Journal of Pharmaceutical Sciences. 70(2):249-251.

16. El-Shaboury S. R., Saleh G. A., Mohamed F. A., Rageh A. H. 2007. Analysis of cephalosporin antibiotics. Journal of Pharmaceutical and Biomedical Analysis. 45:1-19.

17. Pavankumar K., Praba T., Jagadeeswaran M., Caroline Grace A., Sivakumar T. 2013. Spectrophotometric determination for the analysis of cefuroxime axetil in pharmaceutical dosage forms. Analytical Chemistry an Indian Journal. 13(9):347-354.

18. Amir S. B., Hossain M. A., Mazid M. A. 2014. Development and validation of UV spectrophotometric method for the determination of cefuroxime axetil in bulk and pharmaceutical formulation. Journal of Scientific Research. 6(1):133:141.

19. Chavda R. N., Yadav H. N., Hinge M. A., Shing R. D., Patel E. S., andPatel D. R. 2016. Development and validation of analytical method for simultaneous estimation of cefuroxime axetil and linezolid in tablet dosage form. International Journal of Pharma Sciences and Research. 7(4):172-180.

20. Gul S., Akhtar F. 2016. Spectrophotometric method development, validation and estimation of cefuroxime in marketed tablet dosage form. Annals of Chemistry. 1(1):1-6.

21. Rezowanur Rahman Md., Asaduzzaman Md., Ashraful Islam S. M., 2012. Development and validation of UV spectrophotometric method for determination of cefuroxime in pharmaceutical dosage forms. American Journal of Pharmtech Research. 2(4):352-358.

22. Elazazy M. S., Shalaby A., Elbolkiny M. N., Khalil H. M. 2003. Spectrophotometric determination of cefepime hydrochloride, cefoperazone sodium, ceftazidime pentahydrate. cefuroxime sodium and etamsylate using ammonium molybdate. Scientia Pharmaceutica. 71:211-238.

23. Zivanovic L. j., Ivanovic I., Solomun Lj., Zecevic M. 2004. Stability testing of cefuroxime in tablets by micellar liquid chromatography. Chromatographia Supplement. 60:S61-S66. 
24. Can N. O"., Altiokka G., Aboul-Enein H. Y. 2006. Determination of cefuroxime axetil in tablets and biological fluids using liquid chromatography and flow injection analysis. Analytica Chimica Acta. 576:246-252.

25. Zivanovic I., Ivanovic, I., Vladimirov S., Zecevic M. 2004. Investigation of chromatographic conditions for the separation of cefuroxime axetil and its geometric isomer. Journal of Chromatography B. 800:175179.

26. Meenaxi M. M., Yuvaraj D. M., Bhat A. R. 2012. High performance thin layer chromatographic estimation of cefuroxime axetil in bulk and pharmaceutical formulation. International Journal of Pharmaceutical Research. 4(1): 26-28.

27. Kumar P. S., Jayanthi B., Abdul K., Prasad U. V., Kumar Y. N., Sarma P. 2012. A validated high performance liquid chromatography (HPLC) method for the estimation of cefuroxime axetil. Research Journal of Pharmaceutical, Biological and Chemical Sciences. 3(3):223-228.

28. Ranjane P. N., Gandhi S. V., Kadukar S. S., Bothara K. G. 2010. HPTLC Determination of cefuroxime axetil and ornidazole in combined tablet dosage form. Journal of Chromatographic Science. 48:26-28.

29. Ingale P. L., Dalvi S. D. Jadav D. D., Gudi S. V., Patil L. D., Kadam Y. A. 2013. Simultaneous determination of cefuroxime axetil and potassium clavulanate in pharmaceutical dosage form by RP- HPLC. International Journal of Pharmacy and Pharmaceutical Sciences. 5(4):179-181.

30. Modi J. D., Patel P. B., Patel Z. N., Parikh N. N., Chaudhari F. U., Pradhan P. K., Upadhyay U. M. 2014. Development and validation of analytical method for simeltaneous estimation of cefuroxime sodium and potassium clavulanate in bulk and combined dosage form. Pharma Science Monitor. 5(2):117-124.

31. Suthakaran R. Gopinath Srikanth S. Muthu Vadivel S. B., Nannam D. 2013. Analytical profile of raw material and finished product of cefuroxime axetil. Int. J. Res Development in Pharm. and Life Sci. 2(2):371-376.

32. Siddiqui M. R., ALothman Z. A., Wabaidur S. M., Khan M. A., Sarfaraz Alam MD., Sajid Ali MD. 2015. High performance liquid chromatographic method for the quantitative analysis of cefuroxime in pharmaceutical preparations. J. Chil. Chem. Soc., 60:2869-2871.

33. Elias B., Alfeen M. A. 2016. Determination of cefuroxime axetil and cefixime trihydrate in pharmaceutical dosage forms by RP-HPLC method. Pharmaceutical Analytical Chemistry. 2(2):1-5.

34. Kariem A. G., ALgaradi A. A., AL-Kaf A. G. A., Alsammani T. 2016. Development and validation of an RPHPLC method for estimation of cefuroxime axetil and its degradation products in tablets. Pharmacy \& Pharmacology International Journal. 4(5):1-8.

35. Szlagowska S., Kaza M., Rudzki P. J. 2010. Validated HPLC method for determination of cefuroxime in human plasma. Acta Poloniae Pharmaceutica-Drug Research. 67(6):677-681.

36. Shah N. J., Shah S. K., Patel V. F., Patel N. M. 2007. Development and validation of a HPTLC method for the estimation of cefuroxime axetil. Indian Journal of Pharmaceutical Sciences. 69(1):140-142.

37. Rosseel M. T., Peleman R., Van Hoorebeke H., Pauwels R. A. 1997. Measurement of cefuroxime in human bronchoalveolar lavage fluid by high-performance liquid chromatography after solid-phase extraction. Journal of Chromatography. 689(2):438-441. 
38. Aleksić M. M., Lijeskić N., Pantić J., Kapetanović V. P. 2013. Electrochemical behavior and differential pulse voltammetric determination of ceftazidime, cefuroxime-axetil and ceftriaxone. Facta Universitatis - Series Physics Chem. Tech. 11(1):55-66.

39. El-Maali N. A., Osman A. H., Aly A. A. M., Al-Hazmi G. A. A. 2005. Voltammetric analysis of $\mathrm{Cu}$ (II), Cd (II) and Zn (II) complexes and their cyclic voltammetry with several cephalosporin antibiotics. Bioelectrochemistry. 65:95-104.

40. Sawyer D. T., Heineman W. R., Beebe J. M. Chemistry experiments for instrumental methods, Wiley, New York. 198-200 (1984).

41. Sameer A. M., Basavaiah A. K. 2012. Spectrophotometric determination of dothiepin hydrochloride in pharmaceuticals through ion-pair complexation reaction. Chemical Industry \& Chemical Engineering Quarterly. 2:339-386.

42. ICH: Proceedings of the International Conference on Harmonization of Technical Requirement of Registration of Pharmaceuticals for Human Use (2000), ICH Harmonized Tripartite Guidelines. 